\title{
Using Remote Sensing and GIS to Support Drinking Water Supply in Refugee/IDP Camps
}

\author{
Lorenz Wendt ${ }^{1}$, Sylke Hilberg ${ }^{2}$, Jörg Robl ${ }^{2}$, Andreas Braun ${ }^{3}$, Edith Rogenhofer ${ }^{4}$, \\ Daniel Dirnberger ${ }^{2}$, Thomas Strasser ${ }^{1}$, Petra Füreder ${ }^{1}$ and Stefan Lang ${ }^{1}$ \\ ${ }^{1}$ Department of Geoinformatics - Z_GIS, University of Salzburg, Austria · lorenz.wendt@sbg.ac.at \\ ${ }^{2}$ Department of Geography und Geology, University of Salzburg, Austria \\ ${ }^{3}$ Department of Geosciences, University of Tübingen, Germany \\ ${ }^{4}$ Médecins Sans Frontières (MSF), Austria
}

Full paper double blind review

\begin{abstract}
Supplying the population of a refugee or internally displaced persons (IDP) camp with sufficient drinking water is a key concern of humanitarian organisations. This requires information on the geological and hydrogeological situation at the camp site, which is often missing or not available within a reasonable timeframe. Depending on outcrop situation and geological complexity, remote sensing can contribute to a rapid hydrogeological assessment, and greatly reduce the required fieldwork.

In the context of the project EO4HumEn (Earth Observation based services to support humanitarian operations: monitoring population and natural resources in refugee/IDP camps, funded by the Austrian Research Promotion Agency FFG, ASAP 9, Nr. 840081), a team of hydrogeologists and GIS experts supported by Médecins Sans Frontières (MSF) Austria developed a workflow to extract hydrogeological information from easily accessible remote sensing data in a series of short-term desk studies.

This paper provides a condensed, structured protocol on how to produce hydrogeological reconnaissance maps for humanitarian purposes using remote sensing data and GIS. In simple geological settings, these maps can be sufficient to plan and conduct drillings. In more complex situations, fieldwork remains indispensable, but can be guided towards the most suitable locations.
\end{abstract}

\section{$1 \quad$ Problem Setting}

A critical issue in many refugee or internally displaced persons (IDP) camps is the availability of reliable sources for drinking water at close range. While the immediate needs of the camp population can often be met by purification of surface water or water trucking, groundwater is usually the only reasonable and reliable source for the provision of sufficient, clean water in the longer term (MSF 2010). Searching for suitable borehole locations in the vicinity of camp locations is often time and resource consuming, and may be difficult or even dangerous due to the situation on the ground in crisis regions. Therefore, any information based on remote sensing data and derived products that support the delineation of

GI_Forum - Journal for Geographic Information Science, 1-2015.

(c) Herbert Wichmann Verlag, VDE VERLAG GMBH, Berlin/Offenbach. ISBN 978-3-87907-558-4.

(C) ÖAW Verlag, Wien. ISSN 2308-1708, doi:10.1553/giscience2015s449. 
potential borehole sites, and that allow the search area to be narrowed down, is helpful for hydrogeologists in the field.

To define suitable groundwater abstraction sites, field hydrogeologists require some basic pieces of information, usually displayed in a hydrogeological map (table 1). This information often does not readily exist, or is not available to humanitarian organisations within a reasonable time.

Table 1: Information and recommendations shown in hydrogeological reconnaissance maps

\begin{tabular}{|l|l|}
\hline Topic & Map element (with comment) \\
\hline Topography & Shaded relief, contour lines \\
\hline $\begin{array}{l}\text { Geology } \\
\text { Lithology }\end{array}$ & Rock type and its classification as aquifer /aquitard/ aquiclude \\
\hline Folds & Fold axes \\
\hline Lineaments & Brittle or ductile structure, fracture, fault or dike \\
\hline $\begin{array}{l}\text { Regional water flow } \\
\text { Water bodies }\end{array}$ & Permanent water bodies, seasonal water bodies \\
\hline $\begin{array}{l}\text { Recharge and discharge } \\
\text { zones }\end{array}$ & Springs, drainage system \\
\hline $\begin{array}{l}\text { Existing groundwater } \\
\text { installations }\end{array}$ & $\begin{array}{l}\text { Wells and boreholes with depth, water levels, profiles } \\
\text { (if available) }\end{array}$ \\
\hline $\begin{array}{l}\text { Estimated groundwater } \\
\text { elevation and flow direc- } \\
\text { tion }\end{array}$ & Groundwater isohypses (if available) \\
\hline Vegetation cover & (displayed only if indicative for groundwater presence) \\
\hline Soil moisture & (if known from radar) \\
\hline Potential contaminants & Settlements, camps, latrines, landfills, industrial installations, ... \\
\hline Access constraints & Roads, obstacles, borders \\
\hline Recommendations & $\begin{array}{l}\text { Possible sites for field checks, recommended sites for geophysi- } \\
\text { cal investigations (if required), potential drilling sites }\end{array}$ \\
\hline
\end{tabular}

Under conditions of time and data scarcity, remote sensing offers a rapid and efficient approach to create detailed hydrogeological reconnaissance maps (DAVIS and LAMBERT 2002). Reliable hydrogeological predictions within the required time lapse (ten days or less in cases of emergencies) require a structured procedure, consisting of data acquisition, data compiling, and automated and expert based interpretation. It is the scope of this contribution to present an integrated workflow for using remote sensing and GIS to provide drinking water for refugee and IDP camps in emergency cases. 


\section{Data Sources}

\subsection{Geological and Hydrogeological Maps and Borehole Data}

Geological and hydrogeological maps, logs, and borehole-based groundwater information from the study area provide the most valuable information for localizing fertile aquifers. For most parts of the Earth, geological maps of national or continental scale are available, and can help to get a first impression about the relevant geological features. However, detailed geological maps of the surroundings of refugee and IDP camps are difficult to obtain in most cases, because they simply have never been produced, or are not released by the national authorities of the country the camp is located in. Especially considering the strict time requirements for delivering statements about suitable sources of drinking water, these data are not available in the majority of cases.

\subsection{Satellite Imagery}

Although many different sensors with specific technical properties are collecting satellite imagery, the data sets best suitable for hydrogeological mapping are relatively few. Classification of lithology depends, among other criteria, on the spectral properties of different rock types. Some important rock and soil types such as clays/loams, shales, shists and slates, have spectral absorption features in the short wave infrared (near $2.3 \mu \mathrm{m}$; GUPTA 1991). This part of the electromagnetic spectrum is covered by the satellites of the Landsat programme at a spatial resolution of $30 \mathrm{~m} / \mathrm{pixel}$, which is suitable for geological mapping. A further obvious advantage of this dataset is that it is provided free of charge by the U.S. Geological Survey ${ }^{1}$. Another sensor covering this spectral region is ASTER ${ }^{2}$. This data costs approximately $75 €$ per scene of 60 by $60 \mathrm{~km}$. The upcoming European satellite Copernicus Sentinel-2, scheduled to be launched in May 2015, will also cover the shortwave infrared (FLETCHER 2012). In some geological settings, the structural inventory is more important for geological mapping than the spectral properties of the rocks, calling for data with a higher spatial resolution. A growing number of satellites collect data with very high spatial resolutions (VHR) up to $30 \mathrm{~cm} /$ pixel, but their data is not available free of charge. Since mapping of geological features does not require very recent information, imagery provided by Google Maps/Earth $\odot$ or Bing $\odot$ is often sufficient. In geological applications, remote sensing analysis strongly depends on visual interpretation, especially when spectral information in the short wave infrared (SWIR) range is not available. As this applies to most sensors used by Google Maps etc., direct access to the underlying imagery is not required, because more sophisticated analysis methods like band ratios would not be suitable for geological analysis based on this data. The only satellite imagery featuring VHR and SWIR bands currently available is WorldView-3. Its channels in the visible wavelength range reach a spatial resolution of $30 \mathrm{~cm} /$ pixel (panchromatic), the eight bands in the SWIR range in addition to eight bands in the visible to near infrared (VNIR) range have a resolution of up to $3.7 \mathrm{~m}$ and are located between $1195 \mathrm{~nm}$ and $2365 \mathrm{~nm}$ (Digital Globe 2015). This data is only commercially available.

\footnotetext{
$1 \mathrm{http} / / /$ landsat.usgs.gov/

2 http://asterweb.jpl.nasa.gov/
} 


\subsection{Digital Elevation Models}

Digital elevation models (DEM), including digital terrain models (DTM) and digital surface models (DSM) are an important input for hydrogeological mapping. They help in understanding the general geological setup of an area, and allow the direction of surface and likely groundwater flow to be estimated. DEMs can be produced using laser scanning, photogrammetry based on imagery, or radar interferometry. DEMs with a near-global coverage are the ASTER GDEM ${ }^{3}$ (based on optical imagery) and the Shuttle Radar Topography Mission SRTM ${ }^{4}$ (based on interferometry), both with a resolution of 1 arc second (approximately $30 \mathrm{~m} / \mathrm{pixel}$ ). At the end of 2014, the USGS released the SRTM data with 1 arcsecond resolution; previously, only data with a resolution of 3 arc-seconds was globally available. DEMs featuring a higher spatial resolution can be produced based on satellite or airborne imagery, Radar data, or airborne laser scanners, but these datasets are usually not available free of charge and have to be ordered for the specific study area.

\section{Workflow for the Hydrogeological Assessment of a Given Area}

\subsection{General Considerations}

The purpose of hydrogeological mapping is to delineate the location and extent of groundwater-bearing subsurface bodies or structures. Two general situations are distinguished. In unconsolidated sediments/soft rocks, the groundwater flow takes place in the pores of the sediments (HISCOCK \& BENSE 2014). These aquifers are called porous aquifers. In consolidated sedimentary rocks and crystalline or carbonate rocks groundwater follows structures such as fractures, faults, foliations, or karst conduits. These structures are also subsumed as secondary porosity. As crystalline and consolidated sedimentary rocks are sometimes named hard rocks, aquifers in these rock types are often referred to as fractured hard rock aquifers. Groundwater bearing carbonate rocks showing features of karstification are classified as karst aquifers as a special type of fractured hard rock aquifer. The hydraulic conditions in these general types of aquifers are completely different. Hence, different aquifer types require different investigation methods and adequate levels of information detail.

Figure 1 shows the general workflow for hydrogeological reconnaissance mapping that is recommended when using remote sensing methods. Examples for potential and limits of remote sensing for hydrogeological mapping in different climatic and geological settings are shown in Figure 2. The most basic distinction to be made is between porous and fractured aquifers. This is done based on the topographical inventory of the landscape and the presence of hard rock outcrops. Porous aquifers, consisting of loose sediments, are found in topographically flat areas such as valley floors and coastal plains, and lack significant outcrops of hard rocks. In general, geological maps are usually available at the national or continental scale. Although the level of detail of these maps is low in many cases, it is often sufficient for the general discrimination between porous and fractured aquifers.

3 http://asterweb.jpl.nasa.gov/gdem.asp

4 https://lta.cr.usgs.gov/SRTM1Arc 


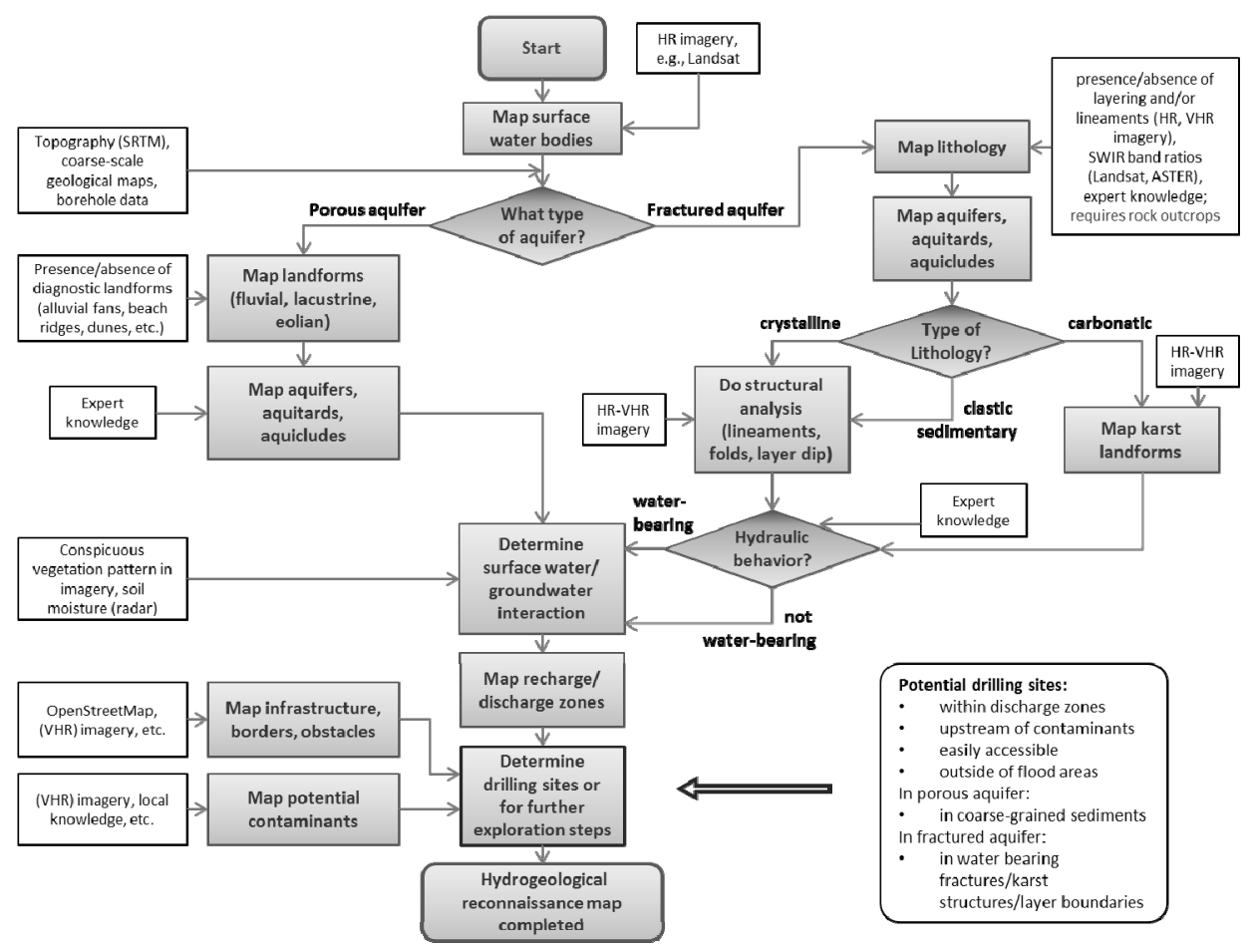

Fig. 1: Recommended workflow for hydrogeological reconnaissance mapping

\subsection{Porous Aquifers}

Porous aquifers differ by their grain-size distributions, reflecting the depositional processes forming these deposits. Hence, unconsolidated sediments are further distinguished according to their depositional environment. Although the exact distribution of sedimentary bodies with different grain sizes and thus permeability in the subsurface can hardly be determined by remote sensing, the expected general types of sediments and their expected hydrogeological properties are characteristic for different sedimentary environments. Therefore, a distinction into fluvial deposits (with high overall permeability), lacustrine, and eolian deposits (with lower permeability), based on the landforms observed in remote sensing imagery is useful. Fluvial deposits consist of coarse-grained sediments such as sands and gravels; they show high hydraulic conductivities and are thus more suitable as drinking water reservoirs than fine-grained lacustrine or eolian sediments with a significantly lower hydraulic conductivity.

In porous aquifers, groundwater fills the pores between the grains, and can be found anywhere within the water bearing layer. Thus, the decision for potential well sites is mainly controlled by the regional and local flow direction with respect to potential pollutants. The determination of groundwater flow direction, and, thus, of recharge and discharge zones, 
comprises a general assessment of the topography to determine the run-off direction. It also comprises the mapping of permanent and seasonal water bodies like lakes and rivers. In arid or semi-arid regions, the presence of vegetation can be an indicator for near surface groundwater, representing discharge zones. Therefore, the production of vegetation index maps or the mapping of soil humidity can be helpful to find suitable groundwater abstraction sites. Known wells and boreholes also have to be mapped.

The interaction between surface waters and groundwater is targeted afterwards. This step includes the mapping of temporarily flooded areas along rivers and shorelines, and other seasonal variations. Multi-temporal satellite imagery, combined with a digital elevation model to find low-lying areas, is employed for this purpose. Temporary lakes without outflow can lead to groundwater infiltration, depending on the surface material and the climatic conditions. An increasing width of a river without obvious tributaries can indicate discharge from a groundwater body into the river.

\subsection{Fractured Aquifers}

Fractured hard rock aquifers display a wide range of hydraulic conditions due to lithological variations and deformation history. In intrusive or metamorphic rocks, groundwater flow is limited to fractures. In sedimentary rocks a combination of fractures and matrix porosity may be responsible for groundwater flow. In carbonatic rocks, karstification is the most important factor that determines hydraulic conductivity. Thus, the determination of the specific lithology is an important step in evaluating aquifer characteristics by remote sensing. The decision for potential borehole sites in fractured aquifers is governed by the location of boundaries between aquifers and aquicludes (lithology dependent), and brittle structures like faults or fractures.

The scientific community has long appreciated the potential of optical remote sensing data for geological mapping. The methods to derive lithology from remote sensing data are described in standard textbooks such as GUPTA (1991) and CAMPBELL \& WYNNE (2011). When using optical remote sensing data to determine geological units it has to be kept in mind that the spectral response is a function of several factors, including the rock type, the state of weathering, moisture content, soil cover, and vegetation, which are interdependent. Spectral responses can vary largely between fresh and weathered rock. Therefore, the spectral response recorded over rock units by multispectral sensors like Landsat 5, 7 or 8 , ASTER, or Sentinel-2 certainly help distinguishing units of different rock types, but is usually not sufficient to identify specific rock types without any ground truth data from the field. Converging evidence from the general geologic setting, the type of landform, the weathering style, the drainage system, and the vegetation cover developed in the investigated unit can - under favorable conditions - allow a distinction of major rock types, but an image derived geological map remains an interpretation, before it has been validated by fieldwork (PROST 2002).

Faults or fractures in rocks occur in scales ranging from a few millimeters to several hundred kilometers. Under favorable conditions, the larger ones can be observed as lineaments in remote sensing data, which are defined as linear surface expressions of a subsurface phenomenon observable in remote sensing data (O'LEARY et al. 1976). Since they may represent preferred fluid pathways, they are first order sites for ground water exploration in hard rock domains (MEIJERINK et al. 2007). In general, aquifers in hard rock domains are 
linked to brittle structures with open fracture spaces that promote the channeling and migration of fluid (water) over large distances, while ductile structures like shear zones in high grade metamorphic rocks or even magmatic lineaments like dykes are characterized by extremely low permeability and therefore represent fluid barriers rather than aquifers. Potential ground water exploration sites are therefore located at regions with a high density of large scale, deep reaching, connected and intersecting brittle structures, so that (a) the hydrological drainage area is large enough to provide fertile aquifers without large seasonal discharge oscillations, and (b) the retention time between recharge and discharge is long to fulfill the quality requirements for drinking water.

Similar to the workflow described for porous aquifers, the investigation process continues with the determination of recharge and discharge zones to estimate groundwater flow direction and interaction between surface waters and groundwater.

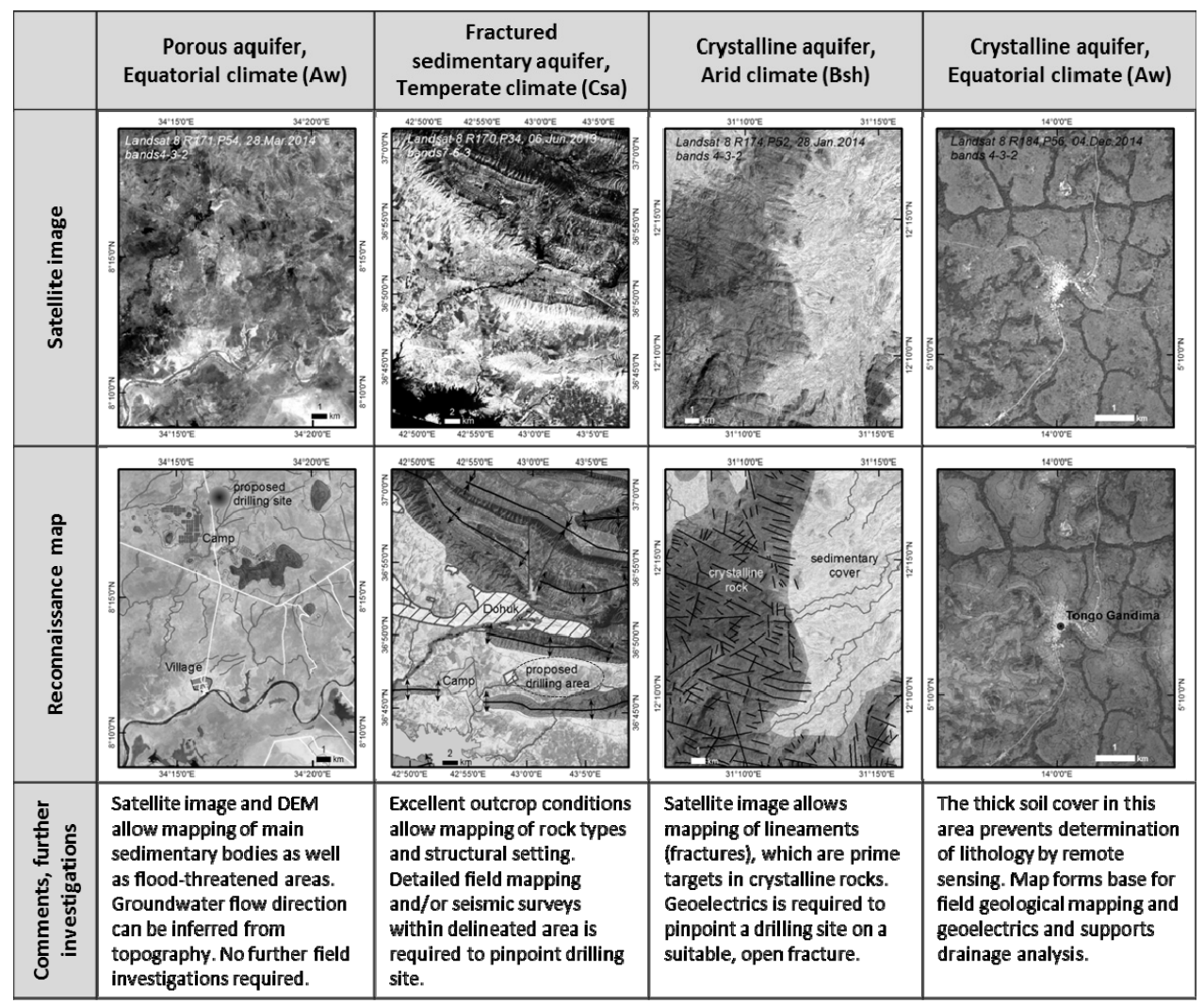

Fig. 2: Examples for satellite-based hydrogeological reconnaissance maps in different climatic and geological settings. Climate codes are Köppen-Geiger classifications according to KOTTEK et al. (2006). 


\subsection{Non-hydrogeological Factors Affecting Drill Site Decisions}

The feasibility of drilling projects not only depends on the geological setting. At least two further factors need to be considered, which are supported by remote sensing data. One is the location of potential groundwater contaminants with respect to the intended drilling site. Contaminants can stem from settlements and refugee/IDP camps, where latrines or livestock might introduce pathogens into the groundwater, but also from factories, mines, landfills or any other sources of pollution.

Drilling of groundwater wells for a refugee/IDP camp or a large village usually requires access with a drilling rig, which is often mounted on or transported by a truck. Therefore, the existing roads and obstacles and areas impassable for ground vehicles are to be mapped. When information on state borders or other access restrictions are known, they should be included in the map product as well.

\section{How to Interpret the Mapped Information}

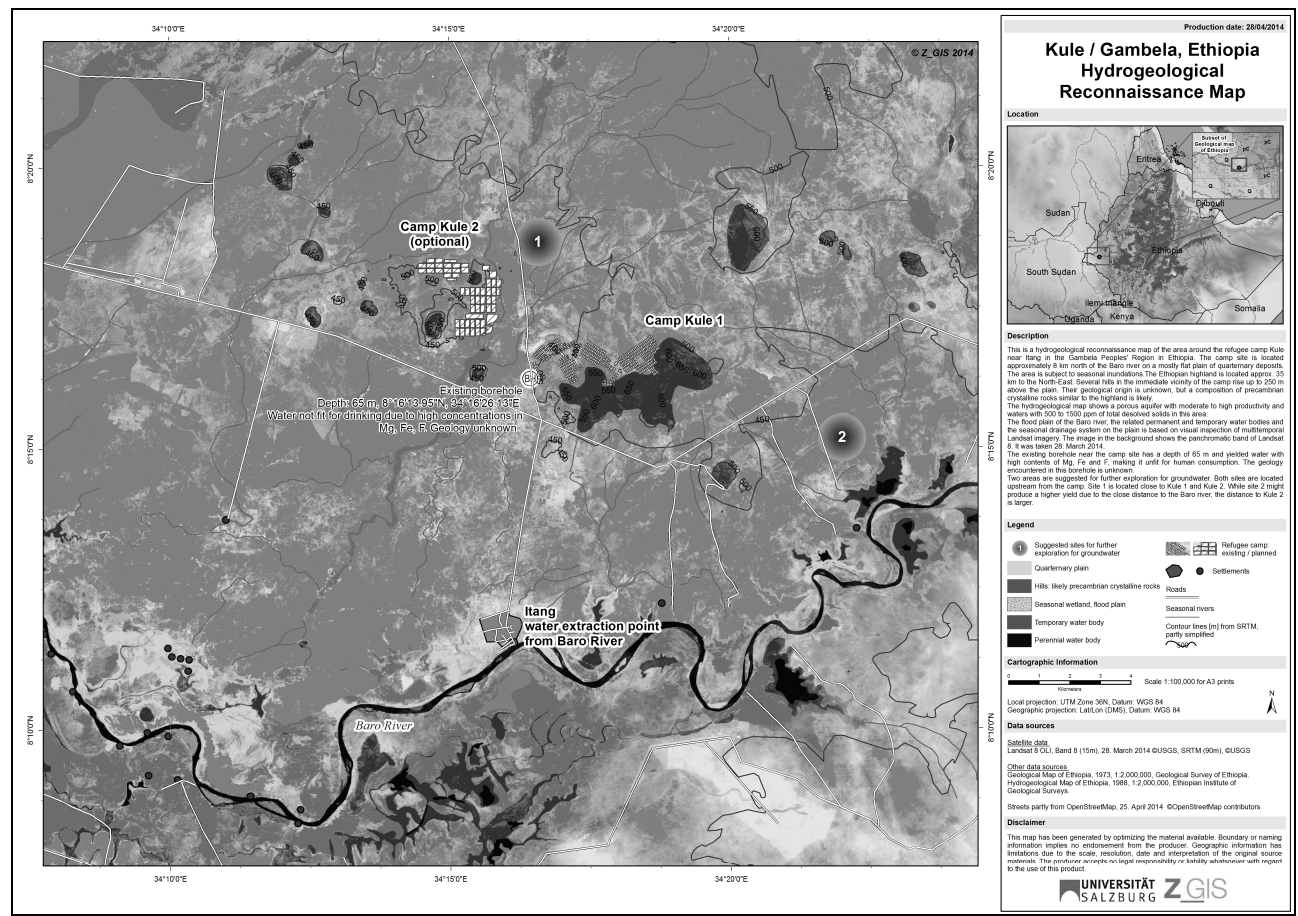

Fig. 3: Example for hydrogeological reconnaissance map for a test site in Ethiopia, which is dominated by a porous aquifer. Two drilling sites or areas are suggested (blue circles), which both fulfil the requirements stated in the text. 
In the case of porous aquifers, the hydrogeological reconnaissance map allows the delineation of an area in which drilling for drinking water is reasonable: in a discharge zone, upstream of pollutants and outside of flood-prone areas. The exact locations of drilling sites can be set in the field and further geological or geophysical investigations are often not required. A precise and detailed desk study as described above allows optimising drilling location and well design to maximize the amount of water, its quality, and protection, and guarantee a suitable distance to the supplied population. Figure 3 shows an example map.

In a hard rock environment potential drill sites must fulfill the following requirements: (1) located within a permeable lithology along water bearing brittle structures, (2) located in a discharge region and (3) outside of flood-prone areas, as well as (4) upstream of potential contaminations, and (5) be easily accessed. The aim of hydrogeological reconnaissance mapping in hard rock environment is to delineate regions that fulfill these preconditions. To define a distinct borehole site, further investigations such as geophysical survey or detailed field mapping are indispensable. Remote sensing methods can help to delineate appropriate investigation areas in order to reduce the amount of fieldwork compared to traditional geological mapping. Recommendations about suitable field methods such as geophysics, drilling or field mapping are included with the hydrogeological reconnaissance maps.

\section{Conclusions}

Remote sensing is well established in geographical and geological sciences. In the humanitarian context, especially disaster relief actions have benefitted from EO-based information as offered by the European Copernicus Emergency Management Service ${ }^{5}$. In this study we described the application of remote sensing for hydrogeological purposes under typical conditions for refugee/IDP crises. The contribution presents an integrated workflow using various remote sensing sources for hydrogeological reconnaissance. The outcome is a hydrogeological map with clearly arranged information that allows optimized field investigations or even the positioning of wells for drinking water abstraction without further timeconsuming field methods.

\section{Acknowledgement}

We thank two anonymous reviewers for their valuable input. Research leading to these results has received funding from the Austrian Research Promotion Agency (FFG) under the Austrian Space Application Programme (ASAP) within the project EO4HumEn (contract no: 840081 ).

\footnotetext{
${ }^{5} \mathrm{http}: / /$ emergency.copernicus.eu/mapping/ems/emergency-management-service-mapping
} 


\section{References}

CAmpbell, J. B. \& WynNe, R. H. (2011), Introduction to Remote Sensing. Guilford Press.

DAVIS, J. \& LAMBERT, R. (2002), Engineering in Emergencies - A practical guide for relief workers 2nd Edition. IZG Publishing, London.

Digital Globe (2015), WorldView-3 Data Sheet. https://www.digitalglobe.com/sites/default/files/DG_WorldView3_DS_forWeb_0.pdf (30.03.2015).

FLETCHER, K. (2012), Sentinel-2: ESA's Optical High-Resolution Mission for GMES Operational Services (ESA SP-1322/2 March 2012). (Ed. ESA). ESA Communications, Noordwijk.

GUPTA, R. P. (1991), Remote sensing geology. Springer-Verlag, Berlin.

Hiscock, K. \& Bense, V. (2014), Hydrogeology: Principles and Practice. 2nd Edition. Wiley.

MSF (2010), Public Health Engineering in Precarious Situations. 2nd Edition. Eds. J. v. d. Noortgate and P. Maes. Médecins Sans Frontières. $414 \mathrm{p}$.

Kottek, M., Grieser, J., Beck, C., Rudolf, B. \& Rubel, F. (2006), World Map of the Köppen-Geiger climate classification updated. Meteorologische Zeitschrift, 15 (3), 25963.

Meijerink, A. M. J., Bannert, D., BatelaAn., O., Lubczynski, M. W. \& Pointet, T. (2007), Remote Sensing Applications to Groundwater. UNESCO, Paris, 304.

O'Leary, D. W., Friedman, J. D. \& Pohn, H. A. (1976), Lineament, linear, lineation: Some proposed new standards for old terms. Geological Society of America Bulletin, 87 (10), 1463-1469.

Prost, G. L. (2002), Remote Sensing for Geologists: A Guide to Image Interpretation. Taylor \& Francis. 